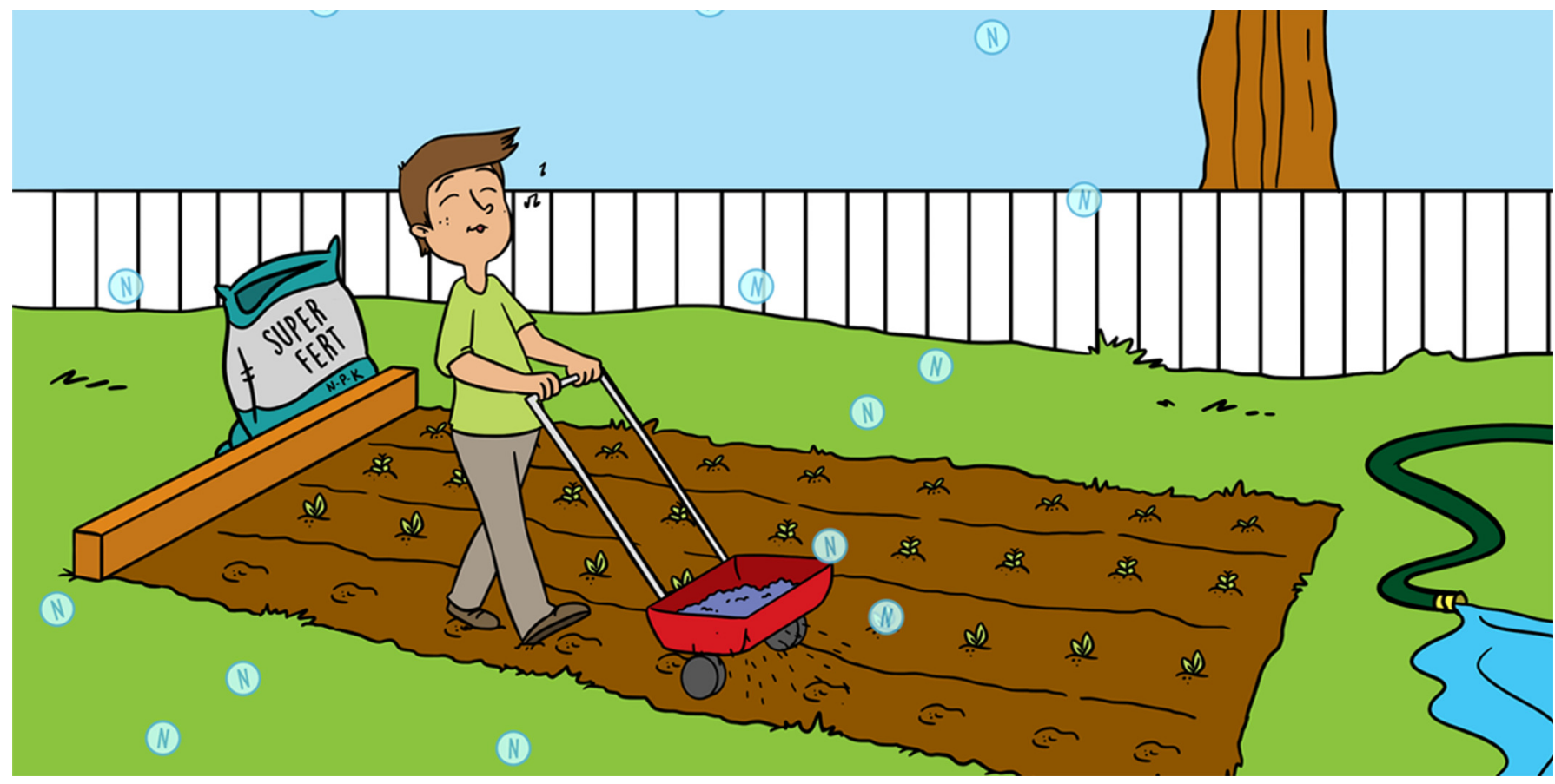

\title{
IS TOO MUCH FERTILIZER A PROBLEM?
}

\section{Christopher J. Sedlacek ${ }^{1,2^{*}}$, Andrew T. Giguere ${ }^{1,3}$ and Petra Pjevac ${ }^{1,4}$}

${ }^{1}$ Division of Microbial Ecology, Centre for Microbiology and Environmental Systems Science, University of Vienna, Vienna, Austria

${ }^{2}$ The Comammox Research Platform, University of Vienna, Vienna, Austria

${ }^{3}$ Center for Microbial Communities, Aalborg University, Aalborg, Denmark

${ }^{4}$ Joint Microbiome Facility of the Medical University of Vienna and the University of Vienna, Vienna, Austria

YOUNG REVIEWER:

(न) ARYAN

AGE: 15
Fertilizers are added to crops in order to produce enough food to feed the human population. Fertilizers provide crops with nutrients like potassium, phosphorus, and nitrogen, which allow crops to grow bigger, faster, and to produce more food. Nitrogen in particular is an essential nutrient for the growth of every organism on Earth. Nitrogen is all around us and makes up about $78 \%$ of the air you breathe. However, plants and animals cannot use the nitrogen gas in the air. To grow, plants require nitrogen compounds from the soil, which can be produced naturally or be provided by fertilizers. However, applying excessive amounts of fertilizer leads to the release of harmful greenhouse gases into the atmosphere and the eutrophication of our waterways. Scientists are currently trying to find solutions to reduce the environmentally harmful effects of fertilizers, without reducing the amount of food we can produce when using them. 


\section{WHAT IS FERTILIZER?}

Fertilizer is any substance or material added to soil that promotes plant growth. There are many fertilizer varieties, and most contain nitrogen (N), phosphorus (P), and potassium (K). In fact, fertilizers sold in stores have an $\mathrm{N}-\mathrm{P}-\mathrm{K}$ ratio on their packaging. Fertilizers are applied all around the world to keep lawns green and to produce more crops in agricultural fields. Fertilizers can be divided into three groups:

1. Mineral fertilizers (phosphorus and potash) are mined from the environment and crushed or chemically treated before being applied.

2. Organic fertilizers (manure and compost) are made from animal feces, and plant or animal decomposed matter.

3. Industrial fertilizers (ammonium phosphate, urea, ammonium nitrate) are produced industrially by humans through chemical reactions.

While organic and mineral fertilizers have been used to increase crop yields in agriculture for a long time, industrial fertilizers are a relatively new development. Even so, industrial fertilizers are the most widely used fertilizers today.

\section{WHY DO WE NEED NITROGEN-CONTAINING FERTILIZERS?}

Nitrogen is one of the elements, or nutrients, that all living things (microorganisms, plants, and animals) need to grow. Although, there is a lot of nitrogen all around us ( $\sim 78 \%$ of the air we breathe), most of the nitrogen on Earth is present as a colorless and odorless gas, called nitrogen gas $\left(\mathrm{N}_{2}\right)$. Unfortunately, plants and animals cannot directly use nitrogen gas. As humans, we get our nitrogen from the food we eat. High protein foods like meat, fish, nuts, or beans are high in nitrogen. Plants get their nitrogen from the soil and nitrogen is the most common nutrient to limit plant growth. There are two ways nitrogen gas is naturally transformed or "fixed" into nitrogen-containing compounds that can end up in soil, without human intervention (Figure 1):

1. Lightning: Lightning strikes generate enough energy to split nitrogen gas in the atmosphere creating nitrogen-containing compounds, which end up in soil.

2. Biological nitrogen fixation: Some microorganisms can use nitrogen gas directly as a nutrient. These specialized microorganisms convert nitrogen gas to ammonium $\left(\mathrm{NH}_{4}{ }^{+}\right)$and are called "nitrogen fixers." Some nitrogen-fixing microorganisms live in soil, and some can form a close relationship with the roots of certain plants, like beans or clover. 
Figure 1

How nitrogen gas fixed into a form that can be used by plants and animals. (A) Lightning strikes can split nitrogen gas (red) in the atmosphere. The newly created nitrogen compounds (blue) then fall down onto soils and naturally fertilize them.

(B) Specialized nitrogen fixing microorganisms in the soil or attached to plant roots can transform nitrogen gas into nitrogen compounds that can be used by plants and animals. (C) Nitrogen gas can be transformed into usable nitrogen compounds industrially with the Haber-Bosch process to make fertilizers, which can be directly applied to soils.

\section{NITROGEN}

\section{FIXATION}

The process of converting nitrogen gas into nitrogen containing compounds. Nitrogen fixation can occur naturally through lightning strikes, be performed by specialized microorganisms, or be accomplished industrially.

\section{HABER-BOSCH} PROCESS

An industrial nitrogen fixation process that can be performed in a laboratory to produce fertilizer components. It was discovered by and is named for the scientists Fritz Haber and Carl Bosch.

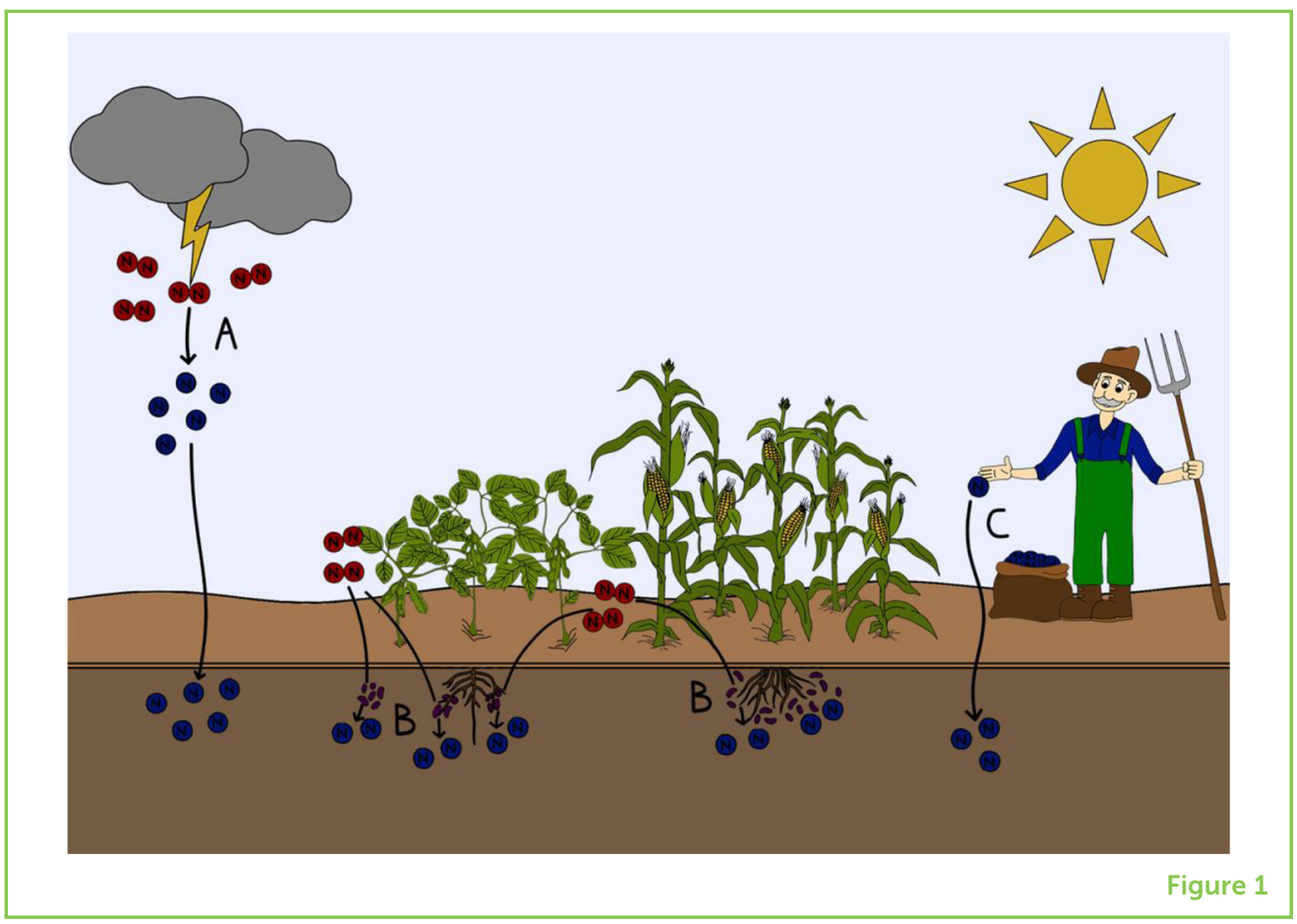

However, even with all this natural nitrogen fixation, low nitrogen levels in soils often still limit plant growth. This is why most fertilizers contain nitrogen compounds and why industrial fertilizers are essential in order to produce enough crops to feed the human population. Humans now add as much or more industrially fixed nitrogen $(\sim 150$ billion kilograms) to the environment each year, than is naturally fixed $[1,2]$. One hundred and fifty billion kilograms ( 230 billion pounds) of anything is hard to imagine, but this is equal to the weight of $\sim 24$ million fully grown adult elephants!

\section{HOW ARE NITROGEN-CONTAINING INDUSTRIAL FERTILIZERS PRODUCED?}

As mentioned, most nitrogen on Earth is present as nitrogen gas, which is unusable for plants and animals. In the early 1900's, scientists discovered how to transform nitrogen gas from the atmosphere into nitrogen-containing compounds that could be used to fertilize soils (Figure 1). This industrial fixation is called the Haber-Bosch process. Almost all the nitrogen in industrial fertilizers is fixed through the Haber-Bosch process.

This industrial fixation of nitrogen is performed in chemical laboratories and large factories all over the world. The Haber-Bosch process requires that nitrogen gas be mixed with hydrogen gas $\left(\mathrm{H}_{2}\right)$ and put under enormous pressure (200 times atmospheric pressure). This is the pressure you would feel if you dove 2,000 meters ( 6,500 feet) underneath the sea, which is a longer distance than 6 Eiffel Towers stacked on top of one another! This pressurized gas mixture is then 
heated to very high temperatures $\left(450^{\circ} \mathrm{C} / 842^{\circ} \mathrm{F}\right)$. Sustaining these high pressures and temperatures requires a huge amount of energy. The Haber-Bosch process is estimated to consume 1-2\% of the world's energy supply each year [2].

\section{WHY DO WE USE SO MUCH NITROGEN-CONTAINING INDUSTRIAL FERTILIZER?}

The short answer is that nitrogen-containing fertilizers help crop plants grow faster and helps to produce more crops. This allows agricultural land to be used more efficiently because fertilized land produces more food. In fact, the invention of industrial fertilizers is one of the main reasons the Earth's population has grown so quickly in the last 60-70 years. Before the widespread use of industrial fertilizers in the 1960's, it took $\sim 123$ years for the Earth's population to double from 1 to 2 billion (1804-1927). However, it only took 445 years (1974-2019) for the Earth's population to double from 4 to 8 billion. Now, we are so dependent on nitrogen fertilization that we would only be able to produce enough food to feed $\sim 50 \%$ of the world's population without it $[1,2]$.

\section{WHERE DOES THE NITROGEN FROM NITROGEN-CONTAINING FERTILIZER END UP?}

The crops take it up of course! Unfortunately, that is not the end of the story. For a more detailed look at all the reactions in the nitrogen cycle, you should read this Young Minds Article: "What is the Nitrogen Cycle and Why is it Key to Life" [3]. In an average agricultural field, only $\sim 50 \%$ of the nitrogen from fertilizers is used by crops [4]. So, while fertilizers make crops grow better and faster, half of the fixed nitrogen we add is lost. Imagine that-we lose the equivalent of 12 million nitrogen elephants ( $\sim 165$ billion pounds) every year! The lost nitrogen can end up in the atmosphere or it can be washed out of the soil and end up in waterways, such as groundwater, streams, lakes, rivers, and oceans (Figure 2). This lost nitrogen causes a variety of environmental problems [2].

GREENHOUSE

\section{GASES}

Gases that trap heat in the atmosphere much like the roof of a greenhouse traps heat to protect the plants growing in it from cold weather and frost.

\section{WHAT ENVIRONMENTAL PROBLEMS DO NITROGEN-CONTAINING FERTILIZERS CAUSE?}

Some soil microorganisms can transform nitrogen provided in fertilizers into nitrogen-containing gases, which get released into the atmosphere like the greenhouse gas nitrous oxide $\left(\mathrm{N}_{2} \mathrm{O}\right)$. Greenhouse gases are one of the main factors accelerating global warming. Nitrous oxide has a warming potential $~ 300$ times greater than the most commonly mentioned greenhouse gas, carbon dioxide $\left(\mathrm{CO}_{2}\right)$. 
Figure 2

Where nitrogen ends up in the environment. Nitrogen from fertilizers that is not taken up by plants can be lost from the soil. (A) Nitrogen can be leached from the soil and enter into waterways either above ground (lakes, streams, rivers, or oceans) or into ground water. Nitrogen leaching into aquatic ecosystems can lead to harmful algal blooms and the eutrophication of waterways. (B) Some microorganisms are able to transform the nitrogen in fertilizer into a variety of different nitrogen containing gases. This gaseous nitrogen can then be lost to the atmosphere in the form of greenhouses gases.

\section{EUTROPHICATION}

\section{A change in an} environment's nutrient status caused by high levels of nutrients (nitrogen or phosphorus) entering waterways (lakes, rivers or oceans). One major consequence is harmful algal blooms and the loss of aquatic life.

\section{HARMFUL ALGAL \\ BLOOMS}

When cyanobacteria and algae grow very fast because of large amounts of nutrients (nitrogen or phosphorus) present in the waters they live in. These cyanobacteria and algae release harmful

chemicals-toxins-into the waterway.

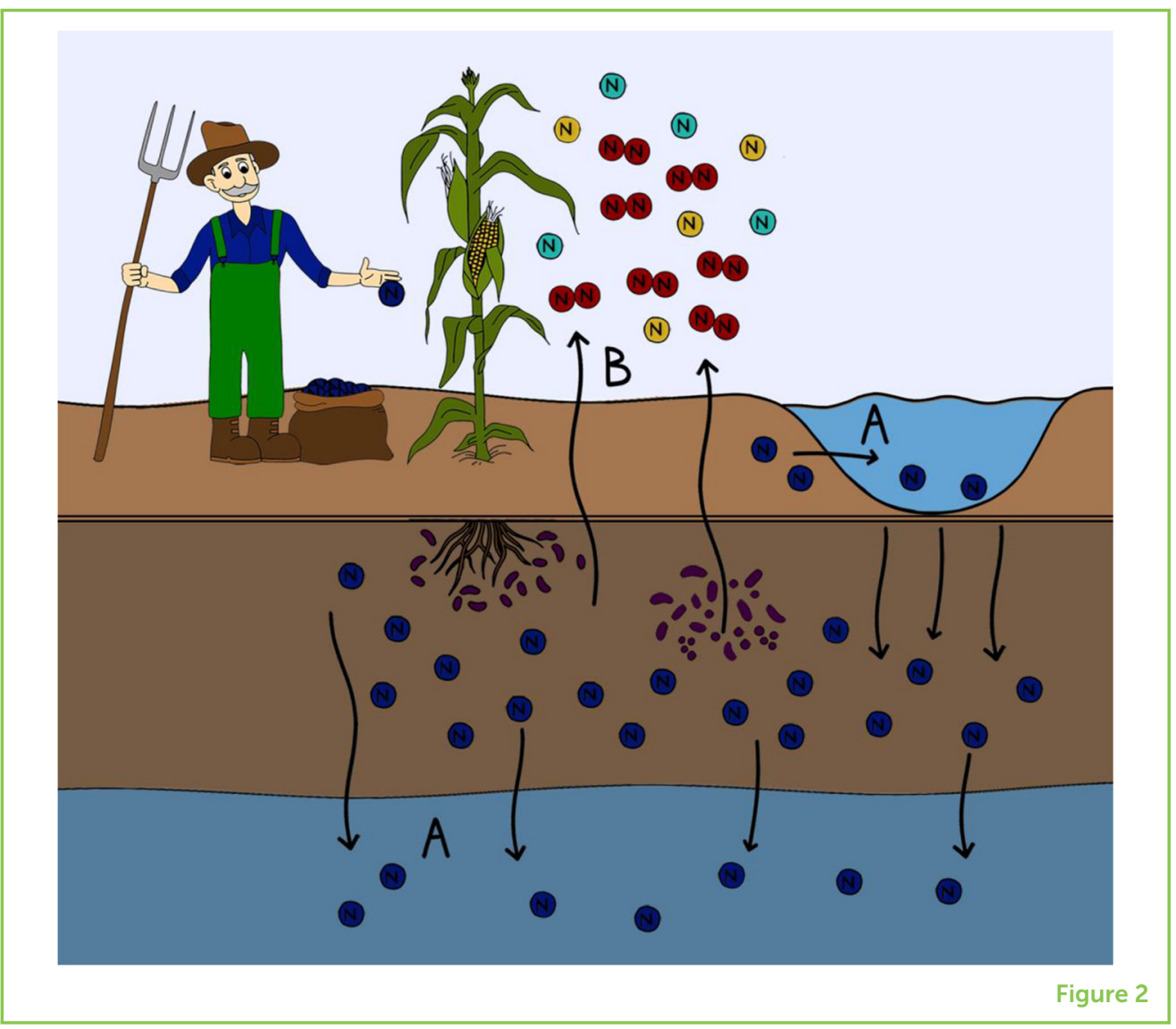

In waterways, the addition of external nutrients (like excess nitrogen) is called eutrophication. Eutrophication is an unwanted fertilization of a waterway and it promotes the growth of microorganisms, algae, and plants, just like the fertilization of soil. However, the fast growth of microorganisms and plants can use up all the oxygen in these waterways and turn them into so-called dead zones, because aquatic animals cannot live without oxygen. Eutrophication can also lead to the growth of algal species that produce toxic chemicals, called harmful algal blooms.

While we need nitrogen from fertilizers in our agricultural soils, we do not need or want additional nitrogen in our atmosphere or waterways. This means we have to balance the positive benefits of nitrogen fertilization (more food) with the negative consequences of excess fertilizer (environmental problems) [1, 2]. Scientists are currently working to find this balance to improve our current situation.

\section{WHAT FERTILIZER RELATED RESEARCH IS CURRENTLY BEING DONE?}

One main goal of fertilizer related research is to decrease the amount of industrially fixed nitrogen that is lost ( $\sim 12$ million elephants worth) to the atmosphere and waterways. This solution is called improving 
Figure 3

Two examples of current research into improving fertilizer efficiency. (A)

Microbiologists and soil scientists are working to improve the growth of nitrogen fixing microorganisms found in the soil, to increase biological nitrogen fixation. This will increase the nitrogen content of the soil (blue). (B) Plant biologists are working to create crop plants that are capable of fixing nitrogen gas (red) directly from the atmosphere into their tissues. This would reduce the need to add nitrogen containing fertilizers to these crops.

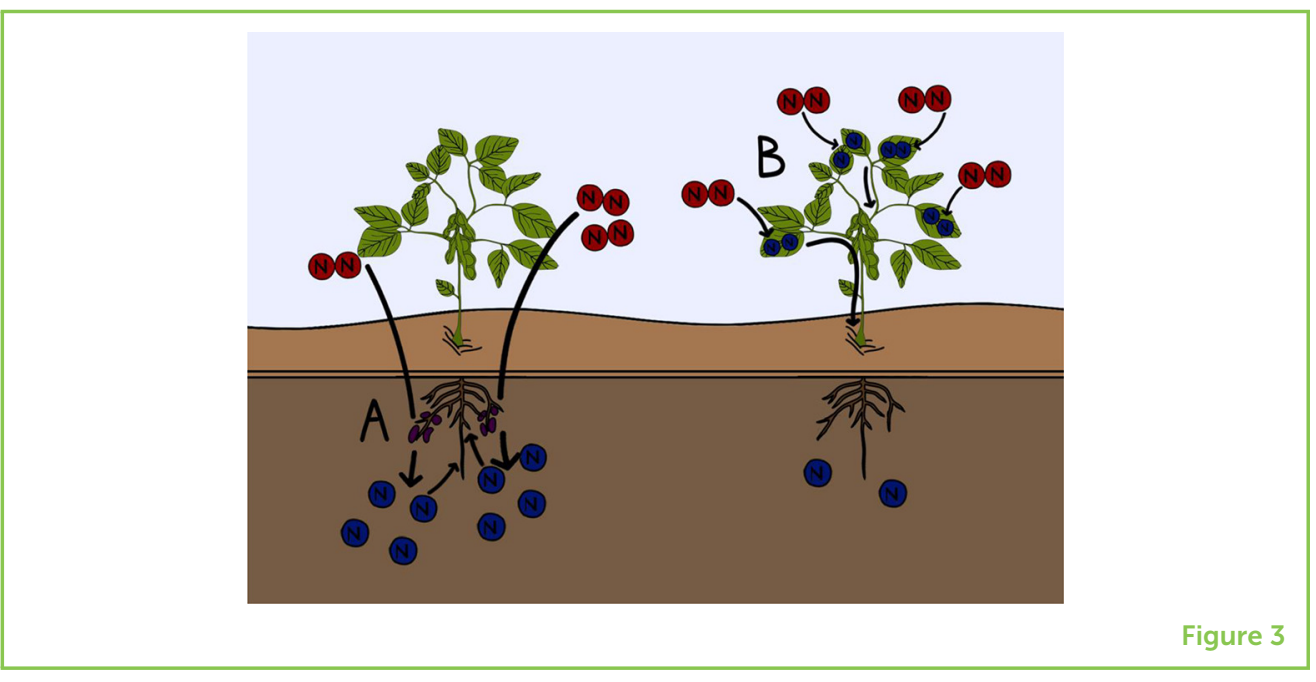

the nitrogen use efficiency of agricultural environments. Here are a few examples of ongoing fertilizer research:

Microbiologists and soil scientists are working on ways to improve field conditions to promote the growth of naturally occurring soil nitrogen-fixing bacteria. In addition, they are also working on ways to prevent the growth of soil microorganisms that contribute to fixed nitrogen being lost to the atmosphere or waterways (Figure 3). Together, this would reduce the overall amount of nitrogen-containing fertilizer needed to get the same crop yield.

Chemists are working on designing fertilizers that are stable in soils over longer time periods and are less likely to be broken down by microorganisms. These slow release fertilizers release little bits of nutrients at a time, so nutrients are available throughout the lifetime of the crops. This approach is still dependent on nitrogen-containing fertilizers, but it would reduce the amount of fertilizer needed and decrease the nitrogen lost.

Plant biologists are trying to genetically engineer crops that would require less nitrogen from fertilizers [5]. These crops would be able to fix their own nitrogen from nitrogen gas, just like the specialized nitrogen-fixing microorganisms. These crops would need less fertilizer to produce the same crop yield (Figure 3).

Computer scientists and soil scientists are working together to design smart fertilization systems, which can monitor soil and air conditions in agricultural fields. These systems can then add small amounts of fertilizer only when needed. This minimizes the amount of fertilizer added, makes fertilizer additions targeted to the crops needs, and decreases the amount of nitrogen lost. 


\section{SUMMARY}

Fertilizers provide crops with essential nutrients like nitrogen, so that the crops grow bigger, faster, and produce more food. However, applying too much fertilizer can be a problem because it leads to the release of greenhouse gases and eutrophication. Scientists are currently trying to find solutions to reduce the amount of fertilizers needed, without reducing the amount of food produced.

\section{ACKNOWLEDGMENTS}

Linnea Kop graciously created and granted permission for the use of her illustrations for all of the figures used in this article.

\section{REFERENCES}

1. Galloway, J. N., Leach, A. M., Erisman, J. W., and Bleeker, A. 2017. Nitrogen: the historical progression from ignorance to knowledge, with a view to future solutions. Soil Res. 55:417-24. doi: 10.1071/SR16334

2. Erisman, J. W., Galloway, J. N., Dice, N. B., Sutton, M. A., Bleeker, A., Grizzetti, B., et al. 2015. Nitrogen: Too Much of a Vital Resource. Science Brief. Zeist: WWF Netherlands.

3. Aczel, M. 2019. What is the nitrogen cycle and why is it key to life? Front. Young Minds 7:41. doi: 10.3389/frym.2019.00041

4. Hirel, B., Tétu, T., Lea, P. J., and Dubois, F. 2011. Improving nitrogen use efficiency in crops for sustainable agriculture. Sustainability 3:1452-85. doi: 10.3390/su3091452

5. Good, A., 2018. Toward nitrogen-fixing plants: a concerted research effort could yield engineered plants that can directly fix nitrogen. Science 359:869-70. doi: 10.1126/science.aas8737

SUBMITTED: 21 July 2019; ACCEPTED: 09 April 2020; PUBLISHED ONLINE: 20 May 2020.

EDITED BY: Mark A. Brandon,The Open University, United Kingdom

CITATION: Sedlacek CJ, Giguere AT and Pjevac P (2020) Is Too Much Fertilizer a Problem? Front. Young Minds 8:63. doi: 10.3389/frym.2020.00063

CONFLICT OF INTEREST: The authors declare that the research was conducted in the absence of any commercial or financial relationships that could be construed as a potential conflict of interest.

COPYRIGHT () 2020 Sedlacek, Giguere and Pjevac. This is an open-access article distributed under the terms of the Creative Commons Attribution License (CC BY). The use, distribution or reproduction in other forums is permitted, provided the original author(s) and the copyright owner(s) are credited and that the original publication in this journal is cited, in accordance with accepted academic practice. 


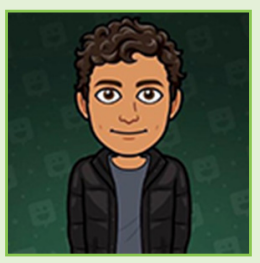

No use, distribution or reproduction is permitted which does not comply with these terms.

\section{YOUNG REVIEWER}

\section{ARYAN, AGE: 15}

Aryan is a budding learner who enjoys reading about scientific advancements especially in the field of climate change and energy. Outside the classroom, Aryan is a fabulous football player full of energy and gusto. One day, he hopes that Manchester United can win the English Premier League, although if they go on losing to Newcastle, that day is far away!

\section{AUTHORS}
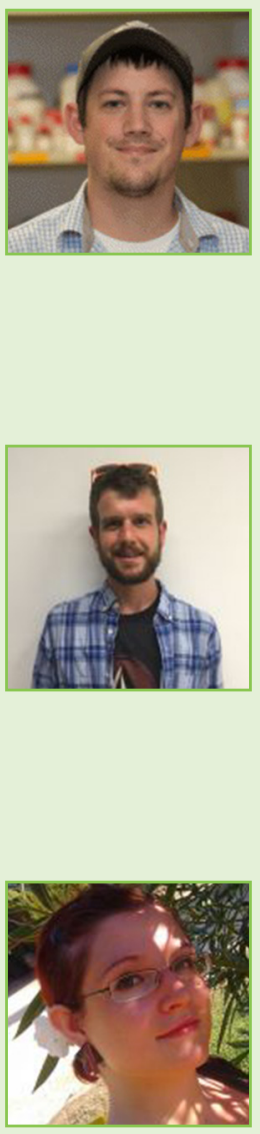

\section{CHRISTOPHER J. SEDLACEK}

I am a Post-doctoral Researcher at the University of Vienna in Austria. My research is focused on understanding how bacteria survive and grow in the environment. I am really interested in microbes called nitrifiers, which are microbes that use nitrogen compounds (like some found in fertilizer) to get all of their energy. The goal of my research is to understand how nitrifiers grow so we can control how and where they grow in the environment. Outside of science I enjoy listening to music and playing ice hockey. *sedlacekc88@aunivie.ac.at

\section{ANDREW T. GIGUERE}

I am a Post-doctoral Researcher at the University of Aalborg in Denmark and the University of Vienna in Austria. My research interests are focused on microorganisms in soil involved in nitrogen cycling. In particular, I want to know more about the physical and chemical factors that control the activity of different groups of microorganisms involved in the nitrogen cycle. I am also interested in how the activity of these tiny microorganisms can have big impacts on agriculture and environmental health. andrew.giguere@univie.ac.at

\section{PETRA PJEVAC}

I am a Senior Scientist at the University of Vienna in Austria. I research how different microorganisms grow and what they can eat. This information is stored in their DNA, their genomes-which is like the hard drive of a microorganism that contains all the data on what it can do. Based on this information, I want to understand why some microorganisms grow better in certain environments than other microorganisms. When not at work, I explore the parks and forests around Vienna with my three children. petra.pjevac@anivie.ac.at 